\title{
Changes in gut hormone levels and negative energy balance during aerobic exercise in obese young males
}

\author{
Shin-ya Ueda, Takahiro Yoshikawa, Yoshihiro Katsura, Tatsuya Usui, Hayato Nakao and Shigeo Fujimoto \\ Department of Sports Medicine, Osaka City University Graduate School of Medicine, 1-4-3, Asahi-machi, Abeno-ku, Osaka 545-8585, Japan \\ (Correspondence should be addressed to T Yoshikawa; Email: tkhr6719@med.osaka-cu.ac.jp)
}

\begin{abstract}
We examined whether changes in gut hormone levels due to a single bout of aerobic exercise differ between obese young males and normal controls, and attempted to determine the involvement of hormonal changes during exercise in the regulation of energy balance (EB) in these obese subjects. Seven obese and seven age-matched subjects of normal weight participated in exercise and rest sessions. Subjects consumed a standardized breakfast that was followed by constant cycling exercise at $50 \% \mathrm{VO}_{2 \max }$ or rest for $60 \mathrm{~min}$. At lunch, a test meal was presented, and energy intake (EI) and relative energy intake (REI) were calculated. Blood samples were obtained at $30 \mathrm{~min}$ intervals during both sessions for measurement of glucose, insulin, glucagon,
\end{abstract}

ghrelin, peptide YY (PYY), and glucagon-like peptide-1 (GLP-1). Plasma levels of PYY and GLP-1 were increased by exercise, whereas plasma ghrelin levels were unaffected by exercise. The areas under the curve (AUC) of the time courses of PYY and GLP-1 levels did not significantly differ between the two groups. In contrast, EI and REI were decreased by exercise in both groups, and energy deficit was significantly larger in obese subjects than in normal controls. The present findings suggest that short-term EB during a single exercise session might be regulated not by increased amounts of these gut hormones per se.

Journal of Endocrinology (2009) 201, 151-159

\section{Introduction}

Excess body weight is a major health problem that affects increasing numbers of people worldwide (Strauss \& Pollack 2001, Ogden et al. 2002, Flegal 2005). Despite the multifactorial etiology of obesity, it seems plausible that behavioral and environmental changes, such as a modern sedentary lifestyle combined with increased dietary intake, have significantly contributed to the recent rapid increase in the prevalence of obesity. It is therefore believed that lifestyle modification based on healthy diet and increased physical activity is of great importance to health (Bianchi et al. 2008). This approach, however, often compels obese patients to fight cravings for food. It thus appears important to control the appetite of obese patients in addition to changing their amount and patterns of food consumption. A substantial body of research on the association of exercise with food intake has suggested that physical activity has an impact not only on energy expenditure but also on variations in appetite and post-exercise energy intake (EI), leading to negative energy balance (EB; Blundell \& King 1998, Hubert et al. 1998).

Recently, there has been growing concern that appetite and energy homeostasis are controlled by a variety of peripheral signals that change in response to starvation or food intake and act in the hypothalamus and brainstem to alter feelings of hunger or fullness so as to determine meal initiation (hunger) or meal termination (satiety; Bray 2000, De Graaf et al. 2004). These feedback signals may include a number of ascending neural inputs (e.g., signaling via the vagal nerve of gastric distension) and hormonal changes, including those of orexigenic or anorexigenic hormones released from gastrointestinal or endocrine organs, including ghrelin, peptide YY (PYY), pancreatic polypeptide (PP), glucagon-like peptide-1 (GLP-1), cholecystokinin (CCK), and oxyntomodulin (Huda et al. 2006, Näslund \& Hellstrom 2007, Wren \& Bloom 2007). While of these, ghrelin is the only orexigenic endogenous hormone, the other peptides and hormones have been found to have anorexigenic effects.

Interestingly, recent studies have revealed inhibitory effects of exercise on the hunger associated with these hormones in healthy subjects (Martins et al. 2007), suggesting the intriguing possibility that exercise may promote a favorable gut hormone profile yielding sustained appetite control and weight loss. Clear understanding of the changes in gut hormones during exercise in obese subjects will aid the development of optimal measures for the prevention and treatment of this condition. To the best of our knowledge, however, few studies have shed light on the effects of exercise on EB and weight reduction through exercise-induced hormonal activities. In addition, it is unknown whether gut hormone release during exercise differs between subjects who are obese and those with normal body weight. 
In the present study, we examined whether changes in plasma gut hormones levels induced by a single bout of aerobic exercise of moderate intensity for $1 \mathrm{~h}$ differed between obese young males and age-matched controls of normal body weight, and determined the involvement of these gut hormones in the regulation of $\mathrm{EB}$ in each subject group.

\section{Materials and Methods}

\section{Subjects}

Fourteen young male subjects (seven obese subjects and seven control subjects with normal body weight) were recruited using the student health records of Osaka City University. Body mass index (BMI) was calculated as weight in kilograms divided by height in meters squared. In accordance with the definition of the Japan Society for the Study of Obesity (Hara et al. 2005, Kondo et al. 2006), we considered participants obese if their BMI was $\geq 25 \mathrm{~kg} / \mathrm{m}^{2}$ and normal in weight if their BMI was $<25 \mathrm{~kg} / \mathrm{m}^{2}$ (BMI range; normal controls: $19 \cdot 1-24 \cdot 7$, obese subjects: $26 \cdot 0-34 \cdot 6)$. All subjects were lifelong non-smokers with a sedentary to moderately active lifestyle (less than one hour of intense exercise per day), and reported stable weight and lack of any special type of diet for the previous 6 months. None had any history of infectious disease for at least the 1 month period preceding the study, and none were taking medications. Subjects with a history of gastrointestinal, endocrine, cardiovascular or psychological disease or type-1 or type-2 diabetes were excluded. The characteristics of the subjects are shown in Table 1. All subjects provided written informed consent for participation in the study, which was approved by the Ethics Committee of Osaka City University.

\section{Exercise performance test}

Prior to the two experimental sessions, subjects performed a recumbent ergometer (Strengthergo, Mitsubishi, Tokyo, Japan) ramp exercise test $(20 \mathrm{~W} / \mathrm{min})$ to determine $\mathrm{VO}_{2 \max }$ after $3 \mathrm{~min}$ rest on the ergometer and a $3 \mathrm{~min} 0 \mathrm{~W}$ warm-up. $\mathrm{VO}_{2 \max }$ was measured with an AE-280S Aeromonitor (Minato Medical Science Inc., Tokyo, Japan). The system consisted of a microcomputer, a hot-wire flow meter, and a gas analyzer, containing a sampling tube, filter, suction pump, and $\mathrm{O}_{2}$ analyzer composed of a zirconium element and an infrared $\mathrm{CO}_{2}$ analyzer. Ventilatory and $\mathrm{O}_{2}$ consumption variables were calculated using the breath-by-breath method. The electrocardiogram and heart rate (HR) were continuously monitored with a Dyna Scope (DS-3140, Fukuda Denshi, Tokyo, Japan) throughout the ramp exercise test. Perceived exertion was rated every minute using the Borg scale.

\section{Experimental protocol}

Subjects took part in two experimental sessions (in exercise and resting conditions) at least 7 days apart. The order of the two sessions was randomized across subjects. The design of the experimental session is shown diagrammatically in Fig. 1. Subjects received a standard evening meal (instant noodles and a piece of cheese: $532 \mathrm{kcal}, 13.9 \mathrm{~g}$ protein, $26.6 \mathrm{~g}$ fat, and $59 \cdot 5 \mathrm{~g}$ carbohydrate) at around 21:00 $\mathrm{h}$ on the day proceeding each of the study days. Subjects came to the laboratory at $8: 30 \mathrm{~h}$ and after a $10 \mathrm{~min}$ rest period, a cannula was inserted into an antecubital vein and a fasting venous blood sample $(t=-60 \mathrm{~min})$ was taken $(20 \mathrm{ml})$. Then a standard breakfast (biscuits, yogurt, and jelly: $560 \mathrm{kcal}, 18.6 \mathrm{~g}$ protein, $21.6 \mathrm{~g}$ fat, and $72.3 \mathrm{~g}$ carbohydrate) was served at $8: 50 \mathrm{~h}$ and the participants remained seated quietly. At 10:00 h, $(t=0 \mathrm{~min})$, the subject either exercised on the recumbent ergometer at $50 \% \mathrm{VO}_{2 \max }$ for $60 \mathrm{~min}$ (exercise session) or sat while allowed to read or write quietly (resting session). During these sessions and after the end of the exercise or resting intervention $(t=0$, $30,60,90,120 \mathrm{~min}$ ), blood samples were obtained at $30 \mathrm{~min}$ intervals. In addition, ratings of subjective feelings of hunger and satiety were reported on a $100 \mathrm{~mm}$ visual analogue scale during the study period $(t=-60,0,30,60,90,120 \mathrm{~min}$; Flint et al. 2000). At 12:00 noon ( $t=120 \mathrm{~min})$, a test meal (instant pasta: $1.15 \mathrm{kcal} / \mathrm{g}$ ) was provided and subjects were instructed to eat as much as they liked until satisfied. In order to exclude the possibility that the amount of food eaten depended on its palatability, we asked all the subjects which foods they liked prior to the study, and selected instant pasta as the test meal. We filled a small bowl with the test pasta and repeatedly filled the bowl with pasta before the participant had emptied it to ensure blindness to the amount of food eaten. No time limit was set for eating under either experimental condition. During the sessions, the subjects and experimenters were instructed to abstain from talking about the meal. Participants were to the extent possible not overtly informed that the true purpose of the present study was to assess feeding responses until they had completed the protocol.

Table 1 Characteristics of subjects

\begin{tabular}{|c|c|c|c|c|c|c|c|}
\hline & Age (years) & Height $(\mathrm{cm})$ & Body weight (kg) & BMI $\left(\mathrm{kg} / \mathrm{m}^{2}\right)$ & Body fat $(\%)$ & Waist $(\mathrm{cm})$ & $\begin{array}{r}\mathbf{V O}_{\text {2max }}(\mathrm{ml} / \mathrm{kg} \\
\text { per minute) }\end{array}$ \\
\hline Normal control & $\begin{array}{l}22 \cdot 4 \pm 4 \cdot 2 \\
\text { N.S. }\end{array}$ & $\begin{array}{l}170 \cdot 8 \pm 2 \cdot 9 \\
\text { N.S. }\end{array}$ & $\begin{array}{l}65 \cdot 3 \pm 7 \cdot 3 \\
-*\end{array}$ & $\begin{array}{l}22 \cdot 4 \pm 2 \cdot 4 \\
{ }_{-*}\end{array}$ & $\begin{array}{l}15 \cdot 1 \pm 4 \cdot 1 \\
\text {-* }^{2}\end{array}$ & $\begin{array}{l}74 \cdot 1 \pm 5 \cdot 6 \\
{ }_{*}^{*}\end{array}$ & $\begin{array}{l}46 \cdot 6 \pm 3 \cdot 9 \\
-_{*}^{*}\end{array}$ \\
\hline Obese & $22 \cdot 9 \pm 3 \cdot 4$ & $172 \cdot 8 \pm 4 \cdot 6$ & $89 \cdot 7 \pm 11 \cdot 9$ & $30 \cdot 0 \pm 3 \cdot 1$ & $26 \cdot 4 \pm 3 \cdot 7$ & $96 \cdot 6 \pm 5 \cdot 3$ & $34 \cdot 0 \pm 6 \cdot 3$ \\
\hline
\end{tabular}

All values are described as mean \pm s.D. ${ }^{*} P<0 \cdot 001$; normal versus obese subjects. 


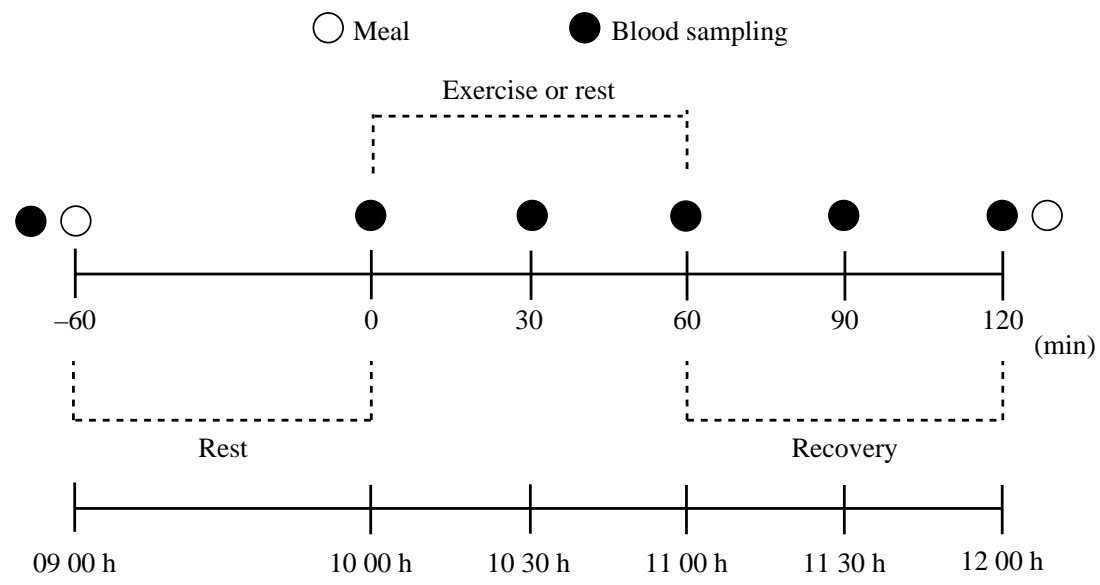

Figure 1 Scheme of the present study.

\section{Energy intake, energy expenditure, and relative energy intake}

After consumption of the test meal, any remaining food was weighed, and the amount determined was subtracted from the premeal value to obtain the total amount of food ingested. Then, absolute EIs from the test meal in the exercise session (EI (Ex)) and resting session (EI (R)) were calculated from the amount of food eaten $(1.15 \mathrm{kcal} / \mathrm{g})$. Energy expenditures during the exercise (EE (Ex)) and resting sessions (EE (R); $t=$ 0 to $120 \mathrm{~min}$ ) were estimated based on metabolic equivalents as previously described (Ainsworth et al. 2000). REI from the test meal corresponds to EI corrected for the energy expended during exercise (REI (Ex)) and resting (REI (R)) sessions, and is calculated as follows

$\mathrm{REI}(\mathrm{Ex})=\mathrm{EI}(\mathrm{Ex})-\mathrm{EE}(\mathrm{Ex}), \quad \mathrm{REI}(\mathrm{R})=\mathrm{EI}(\mathrm{R})-\mathrm{EE}(\mathrm{R})$.

\section{Hormone measurements}

Blood samples were immediately transferred into disodium EDTA-treated tubes for measurement of plasma glucose and hormones. In addition, aprotinin, a potent protease inhibitor, was added to the samples at a concentration of $500 \mathrm{kIU} / \mathrm{ml}$ for measurement of ghrelin. The test tubes were then centrifuged at 3000 r.p.m. for $15 \mathrm{~min}$ at $4{ }^{\circ} \mathrm{C}$ immediately after collection, and the plasma samples were stored at $-80^{\circ} \mathrm{C}$ until hormone assays. Insulin was determined by the fully automated chemiluminescence method. Glucagon level was determined by RIA. Glucose was measured using the enzymatic reference method with hexokinase. Plasma PYY and GLP-1 (GLP-1 (7-36) amide) levels were determined by EIA (Human PYY/GLP-1 EIA kit, Yanaihara Institute Inc., Shizuoka, Japan). The ELISA for PYY quantified the total amount of both PYY ${ }_{1-36}$ and PYY $3-36$. Plasma ghrelin levels were assessed by ELISA (Active Ghrelin ELISA kit, Mitsubishi Kagaku Iatron Inc., Tokyo, Japan). The interassay coefficients of variation for PYY, GLP-1, and ghrelin were each less than $18 \%$. The sensitivities (minimum limits of detection) of PYY, GLP-1, and ghrelin were 0.03 and
$0 \cdot 062 \mathrm{pmol} / \mathrm{ml}$ and $2 \cdot 5 \mathrm{pmol} / 1$ respectively. All sample measurements were performed in duplicate according to the manufacturers' instructions.

\section{Statistical analyses}

All statistical analyses were performed using SPSS for Windows (SPSS Inc., Chicago, IL, USA). All data were normally distributed, and presented as means \pm s.D. The unpaired $t$-test was used for comparison of baseline characteristics between obese and normal control males.

To examine the effects of exercise on sensations of hunger/satiety and on levels of hemoglobin, hematocrit, metabolites, and gut hormones, two-way ANOVA with repeated measures was performed in each body-type group. If statistical significance was detected, post-hoc multiple pairwise comparisons (Tukey-Kramer test) were performed.

Areas under the curve (AUCs) were calculated using the trapezoidal rule to assess total hormonal changes during the exercise session ( $t=0$ to 120 ; $\mathrm{AUC}_{\mathrm{PYY}}(\mathrm{Ex}), \mathrm{AUC}_{\mathrm{GLP}-1}(\mathrm{Ex})$, $\left.\mathrm{AUC}_{\text {ghrelin }}(\mathrm{Ex})\right)$ and during the resting session $(t=0$ to 120 ; $\left.\mathrm{AUC}_{\mathrm{PYY}}(\mathrm{R}), \mathrm{AUC}_{\mathrm{GLP}-1}(\mathrm{R}), \mathrm{AUC}_{\text {ghrelin }}(\mathrm{R})\right)$. In addition, to determine the impact of obesity on EI, REI, and AUC, two-way ANOVA with repeated measures was performed. $P$ values less than 0.05 were considered significant.

\section{Results}

\section{EI and REI}

Mean values of EI and REI after exercise sessions were significantly lower than those after resting sessions (EI and REI; $P<0 \cdot 001)$. In addition, there were significant differences in EI and REI between normal control and obese males (EI, $P=0 \cdot 038$; REI, $P=0 \cdot 021$ ), suggesting the presence of a greater energy deficit due to exercise in obese subjects than in normal control subjects (Table 2). 
Table 2 Energy intake at the test meal and relative energy intake during the exercise and resting sessions

\begin{tabular}{|c|c|c|c|c|c|}
\hline & \multicolumn{2}{|c|}{ Normal control $(n=7)$} & \multicolumn{2}{|l|}{ Obese $(n=7)$} & \multirow[b]{2}{*}{ Significance } \\
\hline & Resting (R) & Exercise (Ex) & Resting (R) & Exercise (Ex) & \\
\hline El (kcal) & $838 \cdot 2 \pm 113 \cdot 6$ & $692 \cdot 3 \pm 106 \cdot 9$ & $944 \cdot 3 \pm 176 \cdot 1$ & $614 \cdot 1 \pm 86 \cdot 9$ & $-^{*},+$ \\
\hline REI (kcal) & $632 \cdot 4 \pm 116 \cdot 4$ & $196 \cdot 3 \pm 108 \cdot 1$ & $661 \cdot 7 \pm 153 \cdot 0$ & $-92 \cdot \overline{5} \pm 111 \cdot 7$ & $-^{*}{ }^{+}$ \\
\hline
\end{tabular}

All values are described as mean \pm s.D. ANOVA for repeated measures. ${ }^{*} P<0 \cdot 001$; effect of session (resting or exercise). ${ }^{\dagger} P<0 \cdot 05$; effect of subject group (normal control or obese males).

\section{Hemoglobin and hematocrit}

No significant changes in either hemoglobin or hematocrit were observed over time during the exercise or resting sessions (Fig. 2). Hemoconcentration was thus unlikely to have occurred during the exercise sessions performed in the present study.

Metabolites, gut hormone concentrations, and measures of appetite

Figure 3 shows the time courses of glucose, insulin, and glucagon levels in blood from $t=-60$ to 120 . No significant difference in levels of glucose was observed between the exercise and resting sessions throughout the course of observation. Despite a significant change in insulin level after breakfast, these levels were not significantly affected by exercise. On the other hand, plasma glucagon levels were increased during the $1 \mathrm{~h}$ exercise period and after the end of exercise compared with those in resting sessions.

Normal control $(n=7)$
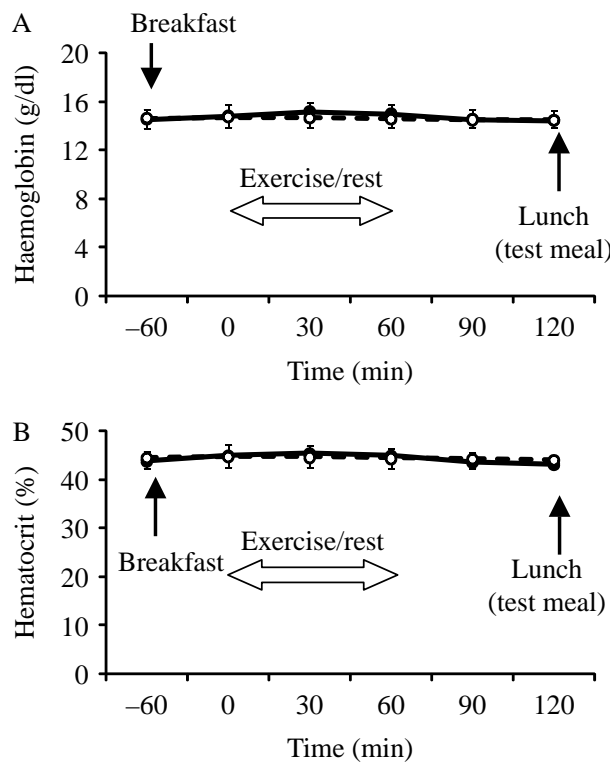

The time courses of gut hormones levels are presented in Fig. 4. Following the onset of exercise $(t=0$ to 120$)$, mean levels of PYY and GLP-1 significantly increased in the exercise session compared with those in the resting session as determined by two-way ANOVA for repeated measures (PYY: normal: $P=0 \cdot 011$, obese: $P=0 \cdot 020$; GLP-1: normal: $P=0.041$, obese: $P=0.002$ ), while plasma ghrelin levels during exercise did not differ from those in the resting session. In addition, during the recovery period $(t=60$ to 120$)$, mean PYY levels fell to those in the resting session, while the increase in level of GLP-1 was maintained compared with the resting session (Fig. 4). No significant changes were observed in hunger, fullness, satiety or motivation to eat in response to exercise in either the normal or obese males (data not shown).

In both of the subject groups, mean AUC values for PYY and GLP-1 were higher in the exercise session than those observed in the resting session (effect of sessions; PYY;

Obese $(n=7)$
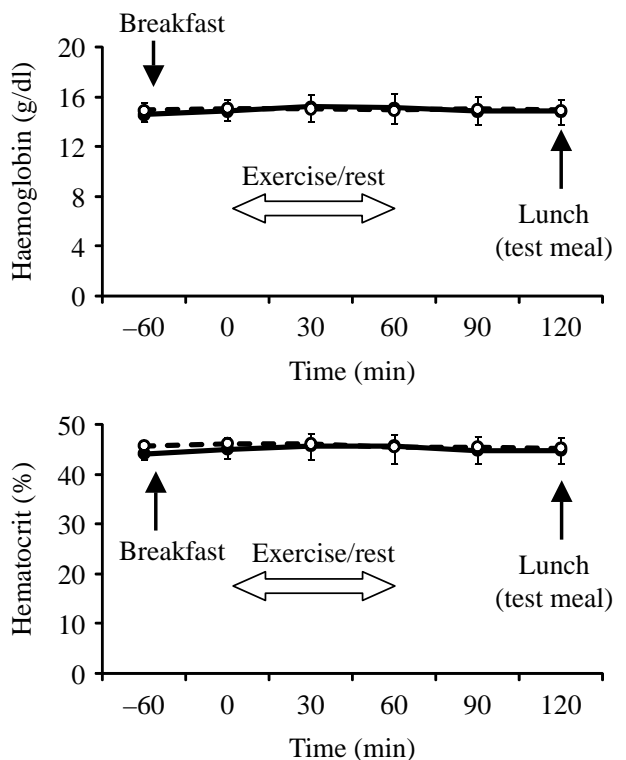

Figure 2 (A) Time course of changes in hemoglobin and (B) hematocrit in normal controls (left panel) and obese subjects (right panel) during exercise $(\mathbf{O})$ and resting $(O)$ sessions. Mean values \pm s.D. are presented. Two-way ANOVA for repeated measures were performed. For each parameter, neither of the two main effects (time and session) nor interaction effect (time $\times$ session) was significant. 

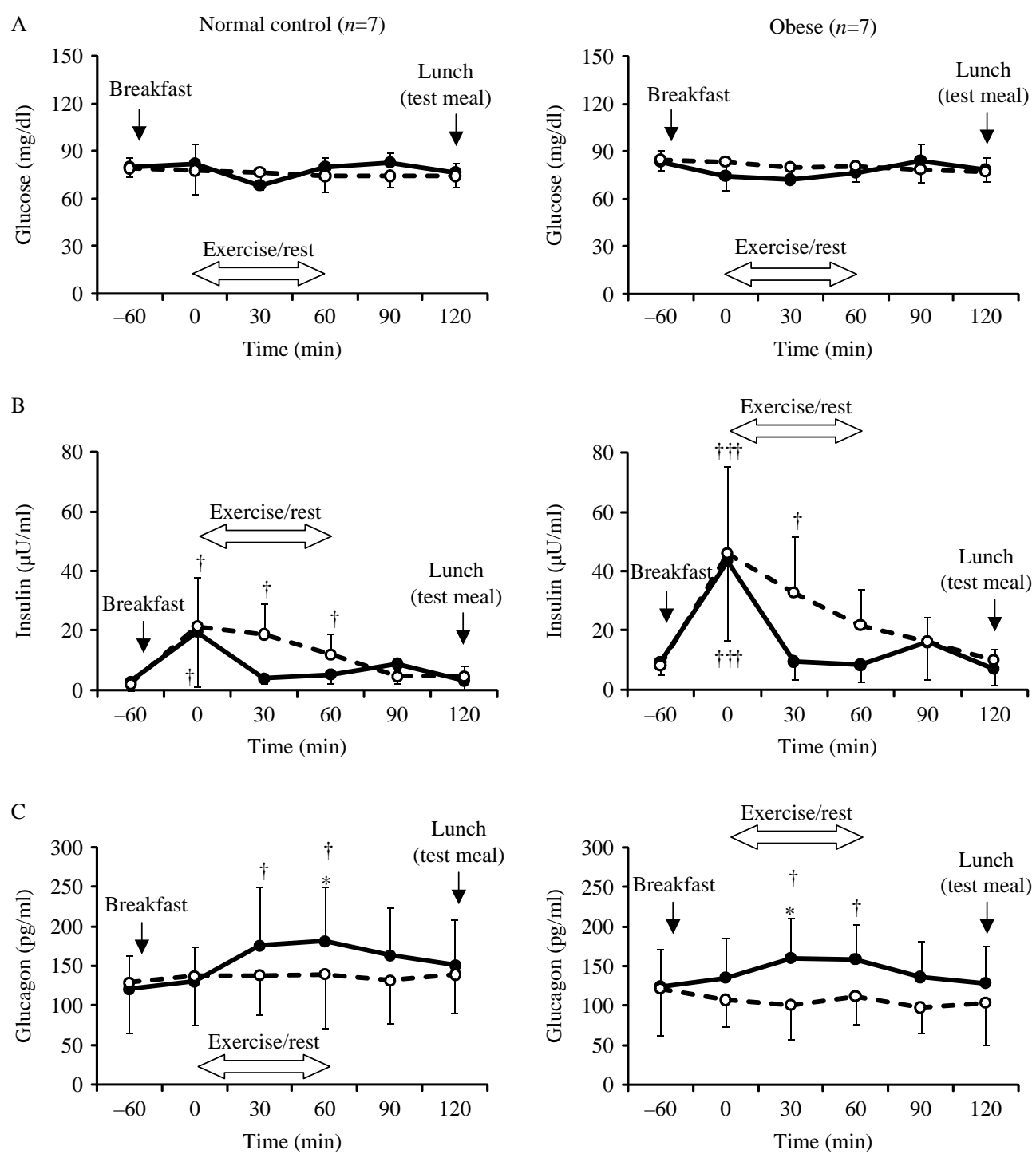

Figure 3 (A) Time course of changes in plasma levels of glucose, (B) insulin, and (C) glucagon in normal controls (left panel) and obese subjects (right panel) during exercise $(\mathbf{O})$ and resting $(O)$ sessions. Mean values \pm s.D. are presented. Two-way ANOVA for repeated measures: (A) main effects (time and sessions) and interaction effect (time $\times$ session); not significant, (B) main effect of time: $P=0 \cdot 001$ (normal controls) and $P<0.001$ (obese), main effect of session and interaction effect of time $\times$ session: $P=0.001$ (both body type groups), (C) main effect of time: $P=0.004$ (normal controls) and $P=0.003$ (obese), main effect of session: $P=0.007$ (normal controls) and $P=0.005$ (obese), and interaction effect of time $\times$ session: $P=0.007$ (normal controls) and $P<0 \cdot 001$ (obese). ${ }^{+} P<0 \cdot 05,{ }^{+++} P<0 \cdot 001$ : versus fasting $(t=-60),{ }^{*} P<0 \cdot 05$ : resting versus exercise session.

$P<0 \cdot 001$, GLP-1; $P<0 \cdot 001$; Table 3). However, the mean values of $\mathrm{AUC}_{\mathrm{PYY}}$ and $\mathrm{AUC} \mathrm{CLP}_{\mathrm{GL}-1}$ in obese subjects were not significantly different from those in normal control subjects (effect of subject groups; PYY; $P=0 \cdot 121$, GLP-1; $P=0 \cdot 168$; Table 3). These findings suggest that, despite the larger energy deficit in obese subjects than in normal control subjects (Table 2), the increases in the levels of anorexigenic hormones PYY and GLP-1 by exercise were not significantly different between these subject groups.

\section{Discussion}

The objectives of this study were to compare changes in the release of gastrointestinal hormones after a single bout of aerobic exercise in young obese subjects with those in normal-weight subjects, and to compare physiological involvement of these hormones in regulation of food intake and EB after exercise in obese subjects with that in normal controls. The following findings were obtained: (1) 

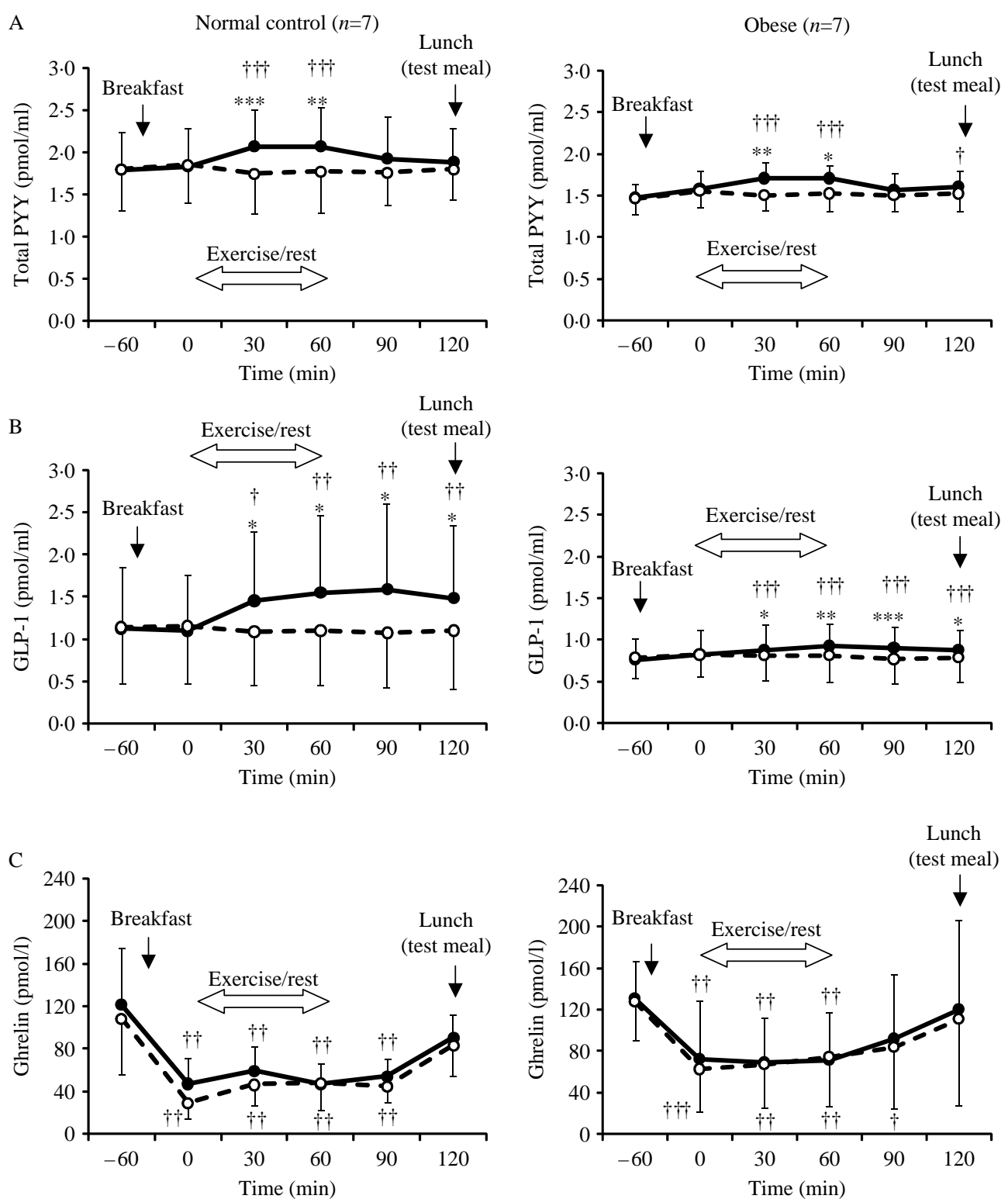

Figure 4 (A) Time course of changes in plasma levels of PYY, (B) GLP-1, (C) and ghrelin in normal controls (left panel) and obese subjects (right panel) during exercise $(-)$ and resting $(O)$ sessions. Mean values \pm s.D. of each parameter are presented. Two-way ANOVA for repeated measures: (A) main effect of time: $P<0 \cdot 001$ (both subject groups), main effect of session: $P=0 \cdot 011$ (normal controls) and $P=0 \cdot 020$ (obese), and interaction effect of time $\times$ session: $P<0.001$ (both body type groups), (B) main effect of time: $P<0 \cdot 001$ (normal controls) and $P=0.007$ (obese), main effect of session: $P=0.041$ (normal controls) and $P=0.002$ (obese), and interaction effect of time $\times$ session: $P<0 \cdot 001$ (both body type groups), (C) main effect of time: $P<0 \cdot 001$ (both subject groups), main effect of session and interaction effect of time $\times$ session: not significant (both subject groups). ${ }^{+} P<0 \cdot 05,{ }^{++} P<0 \cdot 01,{ }^{+++} P<0 \cdot 001$ : versus fasting $(t=-60) .{ }^{*} P<0 \cdot 05,{ }^{* *} P<0 \cdot 01$, $* * * P<0 \cdot 001$ : resting versus exercise session.

In both groups, $1 \mathrm{~h}$ cycling exercise $\left(50 \% \quad \mathrm{VO}_{2 \max }\right)$ significantly increased subsequent release of PYY and GLP-1 in plasma, while plasma levels of ghrelin were not significantly altered. (2) Exercise-induced suppression of EI in obese subjects was significantly larger than in control subjects despite the lack of significant difference in PYY or GLP-1 levels between groups.

There is considerable evidence that PYY, GLP-1, and ghrelin play roles in short-term regulation of appetite and energy homeostasis both in subjects of normal weight 
Table 3 Gut hormones output during the exercise and resting sessions

\begin{tabular}{|c|c|c|c|c|c|}
\hline & \multicolumn{2}{|c|}{ Normal control $(n=7)$} & \multicolumn{2}{|l|}{ Obese $(n=7)$} & \multirow[b]{2}{*}{ Significance } \\
\hline & Resting (R) & Exercise (Ex) & Resting (R) & Exercise (Ex) & \\
\hline $\mathrm{AUC}_{\mathrm{PYY}}(\mathrm{pmol} / \mathrm{ml} \times 120 \mathrm{~min})$ & $213 \cdot 3 \pm 51 \cdot 2$ & $237 \cdot 7 \pm 54 \cdot 1$ & $182 \cdot 3 \pm 23 \cdot 1$ & $197 \cdot 1 \pm 21 \cdot 1$ & $-*$ \\
\hline $\mathrm{AUC}_{\mathrm{GLP}-1}(\mathrm{pmol} / \mathrm{ml} \times 120 \mathrm{~min})$ & $131 \cdot 8 \pm 77 \cdot 6$ & $176 \cdot 8 \pm 104 \cdot 3$ & $96 \cdot 2 \pm 35 \cdot 4$ & $106 \cdot 9 \pm 32 \cdot 3$ & $-*$ \\
\hline $\mathrm{AUC}_{\text {ghrelin }}(\mathrm{pmol} / \mathrm{I} \times 120 \mathrm{~min})$ & $5911 \cdot 8 \pm 1299 \cdot 2$ & $6864 \cdot 7 \pm 1385 \cdot 1$ & $9364 \cdot 3 \pm 5961 \cdot 7$ & $9875 \cdot 8 \pm 6365 \cdot 0$ & \\
\hline
\end{tabular}

All values are described as mean \pm s.D. ANOVA for repeated measures. ${ }^{*} P<0 \cdot 001$; effect of session (resting or exercise). No difference between two body type groups.

and obese subjects. Findings, though controversial, have been obtained on the association of plasma PYY levels with obesity (Batterham et al. 2003, Pfluger et al. 2007). One study demonstrated that the impact of infusion of exogenous $\mathrm{PYY}_{3-36}$ on subsequent caloric intake was similar in obese and lean subjects, suggesting that obese subjects are not resistant to anorexic effects of PYY (Batterham et al. 2003). Excess body weight may be associated with reduction of fasting GLP-1 levels and the postprandial response of GLP-1 (Holst et al. 1983, Ranganath et al. 1996, Holst 2007). In addition, in a meta-analysis of studies on effects of GLP-1 infusion on EI ad libitum (Verdich et al. 2001), GLP-1 infusion was found to dose-dependently reduce EI in lean and obese subjects, indicating equal sensitivity to GLP-1 in the two groups. In human studies on circulating ghrelin (Tschöp et al. 2001, Shiiya et al. 2002), obese subjects had lower plasma concentrations of ghrelin than age-matched lean control subjects. Obese subjects may be more sensitive to stimulation of appetite by exogenous ghrelin, suggesting that inhibition of ghrelin may be therapeutically useful in obese overeating subjects (Druce et al. 2005).

In an elegant study by Martins et al. (2007), $1 \mathrm{~h}$ cycling at $65 \%$ of maximal HR significantly increased plasma levels of the anorexigenic hormones PYY and GLP-1, but not that of orexigenic ghrelin, and resulted in a subsequent decrease in hunger scores in young males and females of normal body weight, although a direct association between increase in levels of these gut hormones and quantitative change in REI was not demonstrated. The potential effects of these gut hormones on energy budget suggest that short-term increase in anorexigenic gut hormones induced by a single bout of exercise might affect subsequent EB in subjects with normal weight. Furthermore, given equivalent increases in plasma levels of these anorexigenic gut hormones during a single bout of moderate-intensity exercise in obese subjects and normal subjects, the increase in anorexigenic hormone release elicited by exercise should play a role in the regulation of EB in both types of subjects. We therefore examined, whether release of these anorexigenic gut hormones increases during a single bout of exercise of moderate intensity and whether this plays a role in the regulation of EB in obese as well as normal subjects. To exclude the possibility that gender (e.g., hormonal condition) affected findings, female subjects were not recruited. In addition, in contrast to a previous study; the $\mathrm{VO}_{2 \max }$ of each subject was measured to ensure that intensity of exercise was set to a moderate level corresponding to aerobic exercise and consistent between the two groups. We used AUC to compare total release and exposure in vivo to gut hormones during and after a single exercise session. Our findings are consistent with those of Martins et al. (2007) with respect to time-course changes in plasma levels of each gut hormone during and after exercise in subjects with normal weight. Furthermore, in mean AUC values of PYY and GLP-1, no significant differences were observed between obese and normal subjects (Table 3), whereas the mean values of EI and REI were significantly lower in obese than in normal subjects (Table 2). Candidate factors contributing to the large energy deficit due to exercise in obese subjects include not only these anorexigenic hormones but also other biological differences between the two groups. Changes in plasma ghrelin concentration during a single bout of exercise did not significantly differ from those observed at rest, consistent with previous findings (Kallio et al. 2001, Dall et al. 2002, Kraemer et al. 2004, Schmidt et al. 2004, Burns et al. 2007) although other studies have reported plasma ghrelin levels decrease with exercise (Toshinai et al. 2007, Malkova et al. 2008) or increased (Erdmann et al. 2007) with exercise. These results might depend on the setting of exercise and the timing of food intake. Our findings suggest that, after meal intake, the impact of a single exercise session on regulation of plasma ghrelin level is less than those on other gut hormones in both obese and normal subjects.

Our study has some limitations. First, we cannot rule out the possibility that cognitive or environmental factors affected our findings, although we carefully attempted to exclude such confounding variables by the choice of study design. When allowed to eat ad libitum, obese subjects consume more food items than do subjects with normal weight (Wing et al. 1978). In fact, in previous studies of appetite in obese subjects, subjects were instructed to eat ad libitum (Dall et al. 2002). However, under these circumstances, amount of food intake can be biased by cognitive factors such as the belief that 'food is a reward for exercise' (King 1999). In the present study, a common test meal of noodles was therefore prepared so that subjects would be unaware of the amount of food intake during the test. In addition, prior to the study, we confirmed that the test meal was palatable to all participants. Second, the mechanisms underlying the time-course changes in plasma PYY and GLP-1 during exercise remain unclear in detail. PYY is rapidly released within $15 \mathrm{~min}$ after food 
intake from the endocrine cells (L cells) in the distal gastrointestinal tract before nutrients have reached this location (Adrian et al. 1985), suggesting the existence of unknown neural or endocrine mechanisms by which PYY release is regulated. Similar mechanisms might also participate in the control of hormone release during exercise. Third, we recruited a small number of subjects in the present study, and could not estimate precise statistical power. A large population study will be necessary to confirm the present results. Furthermore, it will be worthwhile investigating physiological association of gut hormone changes induced by moderate intensity exercise with EB regulation in different population because prevalence and definition of obesity and pathophysiological involvement of BMI with obese-related diseases are likely to vary among countries and ethnicities (Yamamoto et al. 2002).

In conclusion, our findings showed that in obese young adults, a single bout of moderate exercise produced significantly negative EB compared with that in age-matched control subjects of normal weight despite similar increases in plasma PYY and GLP-1 in the two groups. These findings suggest that short-term EB during a single bout of exercise might be regulated not by increased amounts of gut hormones per se. Although, the physiological involvement of exerciseinduced hormonal changes in EB during exercise has recently been examined (Martins et al. 2007), our findings suggest that it is also important to consider multiple other factors that modify the effects of anorexigenic gut hormones in elucidating the mechanisms by which EB is regulated during and after exercise and developing effective programs for weight management.

\section{Declaration of interest}

The authors declare that they have no conflict of interest.

\section{Funding}

None of the authors have a financial relationship with a commercial entity that has an interest in the subject of this manuscript. They declare that they did not obtain any financial support for this study.

\section{Author contribution statement}

All the authors declare that they participated in the acquisition of data, analysis and interpretation of data, and drafting of the manuscript, and that they have seen and approved the final version.

\section{Acknowledgements}

The authors thank all subjects for their participation in the present study, and especially the nurses of the Osaka City University Health Center for their assistance in gathering blood samples. The authors also thank all members of Yanaihara Institute Inc. (Shizuoka, Japan) for their skilled work in the measurement of PYY and GLP-1.

\section{References}

Adrian TE, Ferri GL, Bacarese-Hamilton AJ, Fuessl HS, Polak JM \& Bloom SR 1985 Human distribution and release of a putative new gut hormone, peptide YY. Gastroenterology 89 1070-1077.

Ainsworth BE, Haskell WL, Whitt MC, Irwin ML, Swartz AM, Strath SJ, O’Brien WL, Bassett DR Jr, Schmitz KH, Emplaincourt PO et al. 2000 Compendium of physical activities: an update of activity codes and MET intensities. Medicine and Science in Sports and Exercise 32 S498-S504.

Batterham RL, Cohen MA, Ellis SM, Le Roux CW, Withers DJ, Frost GS, Ghatei MA \& Bloom SR 2003 Inhibition of food intake in obese subjects by peptide YY 3-36. New England Journal of Medicine 349 941-948.

Bianchi C, Penno G, Daniele G, Benzi L, Del Prato S \& Miccoli R 2008 Optimizing management of metabolic syndrome to reduce risk: focus on life-style. Internal and Emergency Medicine 3 87-98.

Blundell JE \& King NA 1998 Effects of exercise on appetite control: loose coupling between energy expenditure and energy intake. International Journal of Obesity and Related Metabolic Disorders 22 S22-S29.

Bray GA 2000 Afferent signals regulating food intake. Proceedings of the Nutrition Society 59 373-384.

Burns SF, Broom DR, Miyashita M, Mundy C \& Stensel DJ 2007 A single session of treadmill running has no effect on plasma total ghrelin concentrations. Journal of Sports Sciences 25 635-642.

Dall R, Kanaley J, Hansen TK, Møller N, Christiansen JS, Hosoda H, Kangawa K \& Jørgensen JO 2002 Plasma ghrelin levels during exercise in healthy subjects and in growth hormone-deficient patients. European Journal of Endocrinology 147 65-70.

Druce MR, Wren AM, Park AJ, Milton JE, Patterson M, Frost G, Ghatei MA, Small C \& Bloom SR 2005 Ghrelin increases food intake in obese as well as lean subjects. International Journal of Obesity 29 1130-1136.

Erdmann J, Tahbaz R, Lippl F, Wagenpfeil S \& Schusdziarra V 2007 Plasma ghrelin levels during exercise - effects of intensity and duration. Regulatory Peptides 143 127-135.

Flegal KM 2005 Epidemiologic aspects of overweight and obesity in the United States. Physiology and Behavior 86 599-602.

Flint A, Raben A, Blundell JE \& Astrup A 2000 Reproducibility, power and validity of visual analogue scales in assessment of appetite sensations in single test meal studies. International Journal of Obesity and Related Metabolic Disorders 24 38-48.

De Graaf C, Blom WA, Smeets PA, Stafleu A \& Hendriks HF 2004 Biomarkers of satiation and satiety. American Journal of Clinical Nutrition 79 946-961.

Hara T, Fujiwara H, Nakao H, Mimura T, Yoshikawa T \& Fujimoto S 2005 Body composition is related to increase in plasma adiponectin levels rather than training in young obese men. European Journal of Applied Physiology 94 $520-526$

Holst JJ 2007 The physiology of glucagon-like peptide 1. Physiological Reviews 87 1409-1439.

Holst JJ, Schwartz TW, Lovgreen NA, Pedersen O \& Beck-Nielsen H 1983 Diurnal profile of pancreatic polypeptide, pancreatic glucagon, gut glucagon and insulin in human morbid obesity. International Journal of Obesity 7 529-538.

Hubert P, King NA \& Blundell JE 1998 Uncoupling the effects of energy expenditure and energy intake: appetite response to short-term energy deficit induced by meal omission and physical activity. Appetite 31 9-19.

Huda MS, Wilding JP \& Pinkney JH 2006 Gut peptides and the regulation of appetite. Obesity Reviews 7 163-182.

Kallio J, Pesonen U, Karvonen MK, Kojima M, Hosoda H, Kangawa K \& Koulu M 2001 Enhanced exercise-induced GH secretion in subjects with Pro7 substitution in the prepro-NPY. Journal of Clinical Endocrinology and Metabolism 86 5348-5352.

King NA 1999 What processes are involved in the appetite response to moderate increases in exercise-induced energy expenditure? Proceedings of the Nutrition Society 58 107-113.

Kondo T, Kobayashi I \& Murakami M 2006 Effect of exercise on circulating adipokine levels in obese young women. Endocrine Journal 53 189-195. 
Kraemer RR, Durand RJ, Acevedo EO, Johnson LG, Kraemer GR, Hebert EP \& Castracane VD 2004 Rigorous running increases growth hormone and insulin-like growth factor-I without altering ghrelin. Experimental Biology and Medicine 229 240-246.

Malkova D, McLaughlin R, Manthou E, Wallace AM \& Nimmo MA 2008 Effect of moderate-intensity exercise session on preprandial and postprandial responses of circulating ghrelin and appetite. Hormone and Metabolic Research 40 410-415.

Martins C, Morgan LM, Bloom SR \& Robertson MD 2007 Effects of exercise on gut peptides, energy intake and appetite. Journal of Endocrinology 193 251-258.

Näslund E \& Hellstrom PM 2007 Appetite signaling: from gut peptides and enteric nerves to brain. Physiology and Behavior 92 256-262.

Ogden CL, Flegal KM, Carroll MD \& Johnson CL 2002 Prevalence and trends in overweight among US children and adolescents, 1999-2000. Journal of the American Medical Association 288 1728-1732.

Pfluger PT, Kampe J, Castaneda TR, Vahl T, D'Alessio DA, Kruthaupt T, Benoit SC, Cuntz U, Rochlitz HJ, Moehlig M et al. 2007 Effect of human body weight changes on circulating levels of peptide YY and peptide YY 3-36. Journal of Clinical Endocrinology and Metabolism 92 583-588.

Ranganath LR, Beety JM, Morgan LM, Wright JW, Howland R \& Marks V 1996 Attenuated GLP-1 secretion in obesity: cause or consequence? Gut 38 916-919.

Schmidt A, Maier C, Schaller G, Nowotny P, Bayerle-Eder M, Buranyi B, Luger A \& Wolzt M 2004 Acute exercise has no effect on ghrelin plasma concentrations. Hormone and Metabolic Research 36 174-177.

Shiiya T, Nakazato M, Mizuta M, Date Y, Mondal MS, Tanaka M, Nozoe S, Hosoda H, Kangawa K \& Matsukura S 2002 Plasma ghrelin levels in lean and obese humans and the effect of glucose on ghrelin secretion. Journal of Clinical Endocrinology and Metabolism 87 240-244.

Strauss RS \& Pollack HA 2001 Epidemic increase in childhood overweight, 1986-1998. Journal of the American Medical Association 286 2845-2848.
Toshinai K, Kawagoe T, Shimbara T, Tobina T, Nishida Y, Mondal MS, Yamaguchi H, Date Y, Tanaka H \& Nakazato M 2007 Acute incremental exercise decreases plasma ghrelin level in healthy men. Hormone and Metabolic Research 39 849-851.

Tschöp M, Weyer C, Tataranni PA, Devanarayan V, Ravussin E \& Heiman ML 2001 Circulating ghrelin levels are decreased in human obesity. Diabetes $50707-709$.

Verdich C, Flint A, Gutzwiller JP, Näslund E, Beglinger C, Hellström PM, Long SJ, Morgan LM, Holst JJ \& Astrup A 2001 A meta-analysis of the effect of glucagon-like peptide-1 (7-36) amide on ad libitum energy intake in humans. Journal of Clinical Endocrinology and Metabolism 86 4382-4389.

Wing RR, Carrol C \& Jeffery RW 1978 Repeated observation of obese and normal subjects eating in the natural environment. Addictive Behaviors $\mathbf{3}$ 191-196.

Wren AM \& Bloom SR 2007 Gut hormones and appetite control. Gastroenterology 132 2116-2130.

Yamamoto A, Richie G, Nakamura H, Hosoda S, Nobuyoshi M, Matsuzaki M, Tan CE, Keech A, Mabuchi H, Horibe H et al. 2002 Risk factors for coronary heart disease in the Japanese-comparison of the background of patients with acute coronary syndrome in the ASPAC study with data obtained from the general population. Asia-Pacific Collaboration on CHD Risk Factor Intervention study. Journal of Atherosclerosis and Thrombosis 9 191-199.

Received in final form 9 January 2009

Accepted 21 January 2009

Made available online as an Accepted Preprint 21 January 2009 